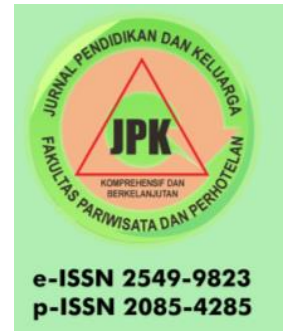

JURNAL PENDIDIKAN DAN KELUARGA

Vol. 11 No. 02, 2019 Page 270-276

DOI: https://doi.org/10.24036/jpk/vol11-iss02

available at http://jpk.ppj.unp.ac.id/index.php/jpk/index

\title{
PENANGANAN KELUHAN TAMU DI NEW D'DHAVE HOTEL PADANG
}

\author{
Budi Ernanda ${ }^{1}$, Hijriyantomi Suyuthie ${ }^{2}$ \\ 1,2 Program Studi Manajemen Perhotelan \\ Jurusan Pariwisata \\ Fakultas Pariwisata Dan Perhotelan \\ Universitas Negeri Padang \\ E-mail : ernandabudi@gmail.com
}

Submitted: 2019-08-127

Accepted: 2019-11-05
Published: 2019-12-31

DOI: https://doi.org/10.24036/jpk/vol11-iss02/675

URL:http://ipk.ppi.unp.ac.id/index.php/ipk/article/view/675

Abstract

The aim of this research is to describe the handling of guests complain who have done at New Dhave Hotel Padang. This research is quantitative descriptive of survey method. The population was taken by guests who had stayed at the New Hotel D'Have Hotel Padang and had conducted a direct assessment to the hotel in the January-June 2018 period, which was attended by 97 people. The technique of sampling is total sampling. The data is used in research are primary data and secondary data. Data collection techniques used were surveys through questionnaires that have been issued validity \& reliability. The data analysis technique used is descriptive analysis. The results showed: 1) Procedural Justice Services with an average value of 3.60 Respondents Achievement Rate (TCR) of $72.00 \%$. Shows that Procedural Justice Services are in the Good category. 2) Interactional Justice average value of 3.54 with Respondents Achievement Rate (TCR) of $70.80 \%$. Establish Interactional Justice in the Good category and 3) Distributive Justice an average score of 23.57 Respondents Achievement Rate (TCR) of 71.34\%. Shows the Good Distributive Justice indicator.Keywords: Work Family Conflict, Employee Perfomance

Keywords: handling, complaints

\begin{abstract}
Abstrak
Penelitian ini dilatar belakangi oleh penanganan keluhan tamu di new d'Dhave Hotel Padang yang masih cukup tinggi. Tujuan penelitian adalah mendeskripsikan penanganan keluhan tamu yang telah ditangani karyawan di New d'Dhave Hotel Padang. Jenis penelitian adalah deskriptif kuantitatif dengan metode survei. Populasi penelitian adalah tamu yang pernah menginap di New d'Dhave Hotel Padang dan pernah melakukan keluhan secara langsung kepada pihak hotel pada periode Januari-Juni 2018 yang berjumlah sebanyak 97 orang. Teknik pengambilan sampel penelitian adalah total sampling. Jenis data yang akan dipergunakan dalam penelitian adalah data primer dan data sekunder. Teknik pengumpulan data yang digunakan adalah survei melaui penyebaran angket yang telah diuji validitas \& realibilitas. Teknik analisis data yang digunakan adalah dengan analisis deskriptif. Hasil penelitian menunjukkan: 1) Procedural Justice Service dengan nilai rata-rata 3,60 Tingkat Capaian Responden (TCR) sebesar 72,00 \%. Menunjukan bahwa Procedural Justice Service dalam kategori Baik. 2) Interactional Justice nilai rata-rata 3,54 dengan Tingkat Capaian Responden (TCR) sebesar 70,80\%. Menunjukan bahwa Interactional Justice dalam kategori Baik
\end{abstract}

his is an open access article distributed under the Creative Commons 4.0 Attribution License, which permits unrestricted use, distribution, and reproduction in any medium, provided the original work is properly cited. $\odot 2017$ by author and Universitas Negeri Padang. 
dan 3) Distributive Justice nilai rata-rata 23,57 Tingkat Capaian Responden (TCR) sebesar 71,34 \%. Menunjukan indikator Distributive Justice kategori Baik.

Kata Kunci: penanganan, keluhan tamu

\section{Pendahuluan}

Hotel adalah salah satu badan usaha akomodasi atau bangunan yang memberikan penginapan, pelayanan, makanan, minuman dan fasilitas jasa. Pelayanan yang diberikan kepada masyarakat umum, baik mereka yang bermalam, maupun yang hanya menggunakan fasilitas yang dimiliki oleh hotel itu sendiri. Hotel adalah perusahan yang dikelola oleh pemiliknya yang menyediakaan pelayanan makanan, minuman dan fasilitas kamar kepada orang-orang yang hendak melakukan perjalanan dan membayar dengan jumlah wajar sesuai dengan pelayanan yang diterima tanpa ada prjanjian khusus (Sulastiyono, 2011). Perusahaan yang harus berjuang untuk mendapatkan 'zero defect' serta kemampuan untuk 'get it right at the first time'. Perusahan yang brgerak dibidang jasa prhotelan sudah pasti cenderung lebih mengandalkaan pelayanan yang sangat baik dan prima disbanding dengan produk yang dijual dalam mnciptakan kepuasan pelanggan. Kepuasan pelanggan dpat tercapai apabila ada jalinan ikatan yang kuat antara pelanggan dengan prusahaan yang dapat memenuhi harapan pelanggan yang akhirnya kepuasan pelanggan teersebut akan menciptakan loyalitass pelanggan terhadap perusahaan). Cara yang dapat mmberikan kepuasan trhadap pelanggan adalah dengan membenahi pelayanaan (Gremler, 2016).

Faktor penyebab komplain terkadang muncul diluar kendali dari pelaku usaha atau organisasi dalam memproduksi suatu barang maupun jasa untuk para konsumen. Produk dalam bentuk jasa memiliki peluang yang lebih besar untuk terjadinya suatu kesalahan yang memunculkan permasalahan daripada produk dalam bentuk barang, bahkan bagi pelaku usaha yang sudah memberikan perhatian lebih terhadap pelayanan jasa pun masih akan memungkinkan terjadinya kegagalan dalam pelayanan. Berikut merupakan data beberapa keluhan yang disampaikan secara langsung oleh tamu kepada New d'Dhave hotel.

Table 1 Data Keluhan Tamu di New d'Dhave hotel Tahun 2016 - 2018

\begin{tabular}{lll}
\hline Tahun & Jumlah Komplain & Keterangan \\
\hline 2016 & 48 & $\begin{array}{l}\text { Sebagian besar komplain mengenai kebersihan } \\
\text { kamar }\end{array}$ \\
\hline 2017 & 94 & $\begin{array}{l}\text { Jenis komplain kebersihan kamar, AV kurang } \\
\text { dingin, serta keterlambatan pesanana makanan } \\
\text { dan minuman }\end{array}$ \\
\hline 2018 & 97 & $\begin{array}{l}\text { Sebagian besar keluhan yaitu mengenai } \\
\text { pelayanankaryawan yang kurang sesuai dengan } \\
\text { harapan dan kebersihan kamar serta } \\
\text { kebersihan lingkungan hotel }\end{array}$ \\
\hline
\end{tabular}

Sumber: HRD Department New d'Dhave Hotel Padang 
Berdasarkan Tabel 1 diatas dapat kita lihat bahwa terjadi peningkatan jumlah komplain yang terjadi di New d'Dhave Hotel pada periode 2016 - 2018. Komplain yang sering disampaikan oleh tamu sebagian besar adalah masalah kebersihan kamar yang selalu terjadi pada tiap tahunya. Hal ini menunjukkan bahwa penanganan keluhan tamu yang dilakukan belum maksimal. Selain itu, Penulis juga menemukan beberapa keluhan dari beberpa tamu yang disampaikan melalui situs Online Travel Agent (Traveloka). Keluhan tersebut secara umum berkaitan pada pelayanan kamar dan pelayanan restoran, yang dilihat pada gambar berikut ini:
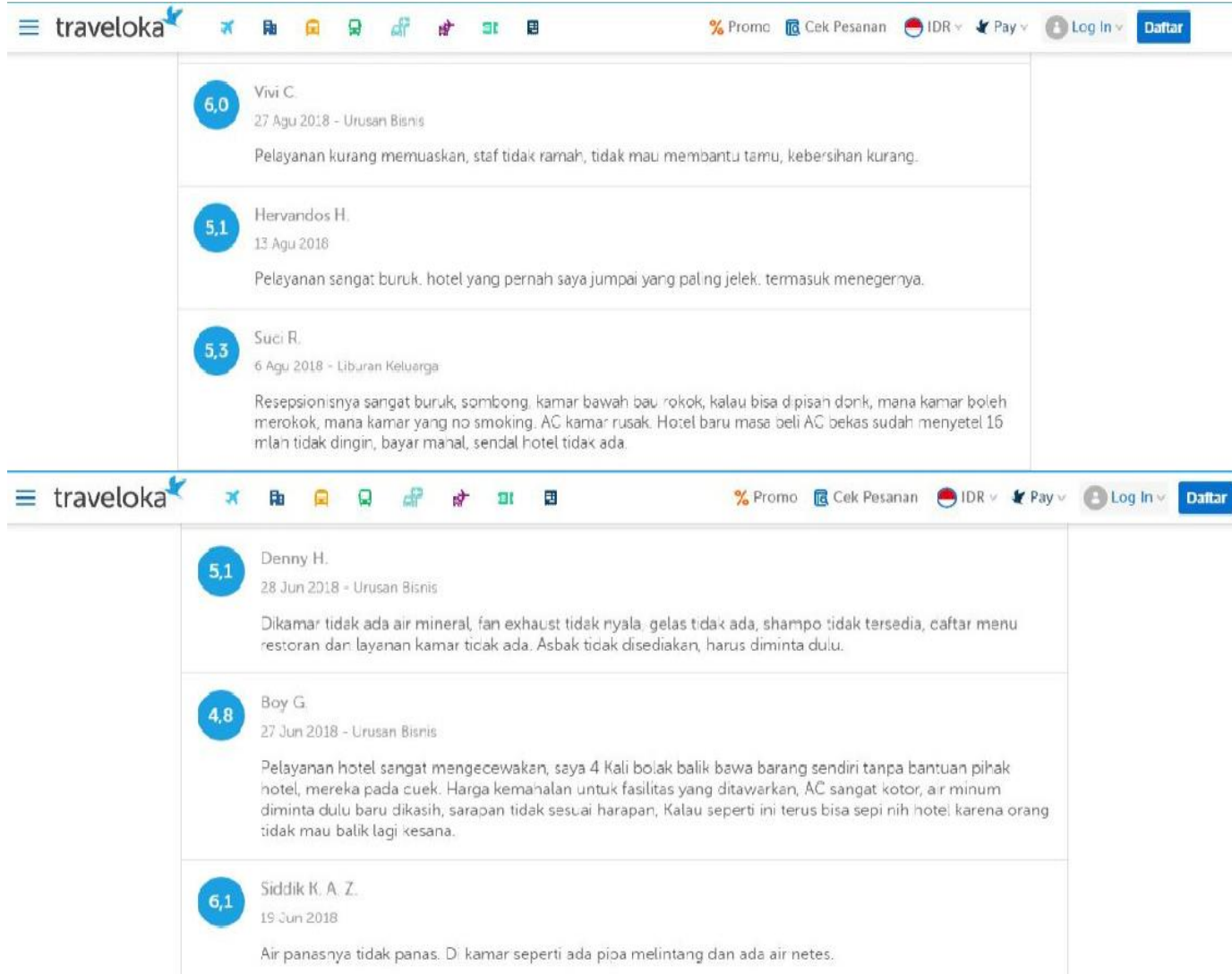

Gambar 1. Keluhan Tamu New d'Dhave Hotel yang Disampaikan Melalui Online Travel Agent (Traveloka)

Masih adanya beberapa keluhan dari konsumen haruslah ditanggapi dengan cara dan respon yang benar. Perusahaan bisa melihat berbagai hasil akhir yang berbeda-beda yang diberikan pelanggan dengan mengikuti tindakan-tindakan yang mungkin terjadi, mulai dari marah hingga gembira. Resiko perpindahan pelanggan sangat tinggi, khususnya ketika terdapat banyak alternatif pesaing. New d'Dhave hotel merupakan hotel yang berada di Kota Padang yang menggunakan strategi berbeda dibandingkan dengan pesaing lainnya. Strategi yang digunakan New d'Dhave hotel berupa merancang suasana hotel menjadi lebih menarik dan menyenangkan. Jasa pelayanan hotel sangat erat hubungannya dengan kepuasan pelanggan, mengingat bahwa 70 persen dari pembelian, ternyata merupakan dasar dari kepuasan konsumen (Melalui elemen-elemen dalam pemulihan layanan, dapat menciptakan

is is an open access article distributed under the Creative Commons 4.0 Attribution License, which permits unrestricted use, distribution, and reproduction in any medium, provided the original work is properly cited. (C2017 by author and Universitas Negeri Padang. 
stimuli-stimuli akan memicu atau mengerakkan pelanggan untuk menginap lebih lama lagi diluar yang mereka rencanakan.

\section{Metode Penelitian}

Jenis penelitian adalah deskriptif kuantitatif dengan metode survei. Populasi penelitian adalah tamu yang pernah menginap di New d'Dhave Hotel Padang dan pernah melakukan keluhan secara langsung kepada pihak hotel pada periode Januari-Juni 2018 yang berjumlah sebanyak 97 orang. Teknik pengambilan sampel penelitian adalah total sampling. Jenis data yang akan digunakan dalam penelitian adalah data primer dan data sekunder. Teknik pengumpulan data digunakan adalah survei melaui penyebaran angket atau kuisioner yang tersusun dan teknik analisis data yang digunakan adalah analisis deskriptif.

\section{Hasil Dan Pembahasan}

\section{Hasil Penelitian}

Hasil penelitian ditemukan skor rata-rata indikator Procedural Justice Service dalam rangka memperbaiki kesalahan pelayanan yang diberikan kepada responden New d'Dhave Hotel Padang yang terdiri-dari 5 pertanyaan, dimana nilai rata-rata 3,60 Tingkat Capaian Responden (TCR) $\quad$ sebesar $72,00 \%$. Menunjukan bahwa indikator Procedural Justice Service dalam rangka memperbaiki kesalahan pelayanan yang diberikan kepada responden New d'Dhave Hotel Padang dalam kategori Baik.

Skor rata-rata indikator Interactional Justice dalam rangka memperbaiki kesalahan pelayanan yang diberikan kepada responden New d'Dhave Hotel Padang yang terdiri-dari 5 pertanyaan, dimana nilai rata-rata 3,54 Tingkat Capaian Responden (TCR) sebesar 70,80 \%. Menunjukan indikator Interactional Justice dalam rangka memperbaiki kesalahan pelayanan yang diberikan kepada responden New d'Dhave Hotel Padang dalam kategori Baik.

Skor rata-rata indikator Distributive Justice dalam rangka memperbaiki kesalahan pelayanan yang diberikan kepada responden New d'Dhave Hotel Padang yang terdiri-dari 3 pertanyaan, dimana nilai rata-rata 3,57 Tingkat Capaian Responden (TCR) sebesar 71,34 \%. Hal ini menunjukan bahwa indikator Distributive Justice dalam rangka memperbaiki kesalahan pelayanan yang diberikan kepada responden New d'Dhave Hotel Padang dalam kategori Baik.

\section{Pembahasan}

\section{Procedural Justice Service pada New d'Dhave Hotel Padang}

Berdasarkan hasil penelitian ditemukan skor rata-rata indikator Procedural Justice Service dalam rangka memperbaiki kesalahan pelayanan yang diberikan kepada responden New d'Dhave Hotel Padang yang terdiri-dari 5 pertanyaan, dimana nilai rata-rata 3,60 Tingkat Capaian Responden (TCR) sebesar 72,00 \%. Menunjukan bahwa indikator Procedural Justice Service dalam rangka memperbaiki kesalahan pelayanan yang diberikan kepada responden New d'Dhave Hotel Padang dalam kategori Baik.

Pada indikator Procedural Justice Service pertanyaan yang memiliki nilai TCR terendah adalah pertanyaan nomor 1 yaitu puas dengan cara pihak hotel menangani keluhan saya tepat waktu dengan rata-rata 3,55 Tingkat Capaian Responden (TCR) sebesar 70,93 \%, Pertanyaan ini berada pada kategori sudah baik artinya pelanggan sudah puas dengan cara 
pihak hotel menangani keluhan pelanggan. Procedural justice lebih mengacu kepada proses penanganan yang terjadi dalam menyelesaikan masalah yang timbul pada aspek-aspek aksesibilitas, waktu atau kecepatan penanganan, kontrol proses, penundaan dan fleksibilitas untuk beradaptasi dengan kebutuhan dalam penanganan keluan konsumen.

Sesuai teori Agusnawar (2004: 85), langkah-langkah yang harus diperhatikan dalam mengatasi keluhan tamu adalah: 1) Mendengarkan dengan penuh perhatian ketika tamu mengatakan keluhannya, dengarkan dan kasih perhatian kepada tamu. Ketika tamu menunjukan ketidakpuasan, jangan dibantah atau disela argumentasi Tamu. Sebaiknya berikan rasa simpati kepada tamu bahwa itu memang terjadi. 2) Receptionist tetap tenang, Karena receptionist harus ramah dan tetap tenang, tidak gugup, panik ataupun marah. Usahakan menerima, memahami, dan merasakan yang dirasakan oleh tamu. Meminta maaf dan merasa menyesal dengan kejadian yang tidak diinginkan. 3) Sopan kepada tamu. Anggap keluhan tamu itu kesempatan untuk menciptakan hubungan yang baik dan suasana menjadi lebih baik untuk tamu. Tunjukan sikap terpuji serta tetap sopan dan ramah dalam menghadapi tamu yang sedang marah. Kemarahan dan kegusaran tamu akan mereda. 4) Pelajari dan mencari tahu penyebab keluhan tamu tersebut. Apabila masalah yang timbul karna tamu itu sendiri, hendaknya jangan menyalahkan tamu dan menjelaskan ke tamu agar mengerti permasalahan yang sebenarnya terjadi. Dan 5) Mencatat semua yang dikeluhkan oleh tamu. Mencatat semua yang dikeluhkan oleh tamu artinya Menunjukan maksud baik kepada tamu bahwa keluhanya akan segera ditanggapi.

Perilaku keluhan konsumen diakui para pelaku usaha sebagai kesempatan dan cara untuk memperbaiki kualitas produk/jasa yang ditawarkannya kepada konsumen, dan juga memberikan dampak yang positif untuk perilaku pelanggan pada kesempatan berikutnya. Hasil penelitian ditemukan konsumen sudha merasa puas dengan cara hotel menangani keluhan saya tepat waktu, dalam menyelesaikan keluhan pelanggan dan menyelesaikan dengan cepat, pihak hotel melakukan pencacatan, dan mendokumentasikan keluhan yang saya sampaikan dan pelanggan sudah puas karena keluhan yang sampaikan mendapatkan tindak lanjut.

\section{Interactional Justice pada New d'Dhave Hotel Padang}

Berdasarkan hasil penelitian ditemukan skor rata-rata indikator Interactional Justice dalam rangka memperbaiki kesalahan pelayanan yang diberikan kepada responden New d'Dhave Hotel Padang yang terdiri-dari 5 pertanyaan, dimana nilai rata-rata 3,54 Tingkat Capaian Responden (TCR) sebesar 70,80 \%. Menunjukan indikator Interactional Justice dalam rangka memperbaiki kesalahan pelayanan yang diberikan kepada responden New d'Dhave Hotel Padang dalam kategori Baik.

Pada indikator Interactional Justice Service pertanyaan yang memiliki nilai TCR terendah adalah nomor 7 yaitu pihak hotel dalam memberikan penjelasan yang baik dan sopan dengan rata-rata 3,53 Tingkat Capaian Responden (TCR) sebesar 70,52 \%, pertanyaan ini berada pada kategori sudah baik artinya pihak hotel telah dalam memberikan penjelasan yang baik dan sopan.

Menurut Soenarno (2006: 325), "Untuk mengatasi keluhan, kita dapat menggunakan metode yang lazim disingkat sebagai HEAT yaitu 1) Hear them out. Mendengarkan keluhan yang disampaikan oleh tamu. Walaupun prilaku tamu saat menyampaikan keluhan 
menyinggung dan menyakitkan perasaan Jangan menanggapi yang dikeluhkan oleh tamu dengan emosi. 2) Empathize. Rasa empati terhadap tamu, ikut merasakan yang dirasakan tamu dan berusaha mencari solusi. Contoh kalimat yang menunjukkan rasa empati kepada tamu adalah, I understand how do you feel, if I were you I will be upset, etc. 3) Apologize. Permintaan maaf dengan sungguh-sungguh kepada tamu. Ketika menangani yang dikeluhkan oleh tamu, jangan saling menyalahkan. Staff harus minta maaf kepada tamu karena membuat tamu tidak nyaman. "sorry for the inconvenience." 4) Taking proper action and follow up.

Dimensi terakhir dari perceived justice adalah interactional justice yang merupakan hubungan interpersonalantara karyawan atau pelaku usaha dengan konsumen terkait perilakunya dalam menangani permasalahan yang muncul. Interactional justice menilai keadilan berdasarkan interaksi pribadi yang dilakukan oleh konsumen dengan pelaku usaha dalam proses penanganan kegagalan layanan. Persepsi konsumen terkait perilaku pelaku usaha diantaranya adalah cara pelaku usaha berempati, keramahan dan kesopanan menanggapi komplain, memberikan penjelasan dan meminta maaf atas kegagalan layanan, serta kejujuran dan kemampuan pelaku usaha dalam menanggapi komplain. Berdasarkan uraian diatas dapat disimpulkan bahwa interactional justice adalah penilaian keadilan berdasarkan interaksi pribadi antara pihak hotel dengan tamu dalam menangani masalah. Hasil penelitian terlihat pelanggan sudah cukup puas dengan tindakan pihak hotel dalam memperlakukan pelanggan dengan ramah, pihak hotel memberikan penjelasan yang baik dan sopan dari pihak hotel, perlakuan hormat pihak hotel kepada pelanggan.

\section{Distributive Justice pada New d'Dhave Hotel Padang}

Berdasarkan hasil penelitian ditemukan skor rata-rata indikator Distributive Justice dalam rangka memperbaiki kesalahan pelayanan yang diberikan kepada responden New d'Dhave Hotel Padang yang terdiri-dari 3 pertanyaan, dimana nilai rata-rata 3,57 Tingkat Capaian Responden (TCR) sebesar 71,34 \%. Menunjukan indikator Distributive Justice dalam rangka memperbaiki kesalahan pelayanan yang diberikan kepada responden New d'Dhave Hotel Padang dalam kategori Baik. Pada indikator Distributive Justice pertanyaan yang memiliki nilai TCR terendah adalah nomor 13 yaitu keseluruhan, kompensasi yang saya terima dari pihak hotel sudah adil dengan rata-rata 3,53 Tingkat Capaian Responden (TCR) sebesar $70,52 \%$, Pertanyaan ini berada pada kategori sudah baik artinya pihak hotel memberikan ganti rugai atas keluhan yang diajukan konsumen secara adil.

Distributive justice merupakan penilaian individu tentang keadilan yang dirasakan yang berfokus pada kesetaraan/ekuitas dimana individu tersebut membandingkan antara input dengan outcome maupun membandingkan keuntungan yang diterima (untuk mendapatkan kesetaraan skor. Hal serupa juga dinyatakan oleh Hood (2014) bahwa distributive justice merupakan keadilan yang melibatkankeputusan oleh dua pihak atau lebih yang saling terkait sebagai hasil nyata adanya ketidaksetaraan yang menimbulkan sengketa dan negosiasi. Namun ketika konsumen dan pelaku usaha kemudian telah mencapai kesetaraan maka selanjutnya adalah kepuasan pada pihak-pihak yang terkait . Hal yang pelaku usaha dapat lakukan untuk meyelesaikan permasalahan tersebut adalah dengan menawarkan ganti rugi, diantaranya dengan memberikan pengembalian dana, pertukaran, permintaan maaf, kredit, diskon pada pembelian selanjutnya, perbaikan, dan lain-lain. Hasil penelitian terlihat pada indikator Distributive justice, pelanggan telah merasa puas karena menerima ganti rugi yang 
memadai sebagai kompensasi keluhan yang saya ajukan, penawaran diskon kamar jika saya menginap kembali.

\section{Simpulan Dan Saran}

\section{Simpulan}

Hasil penelitian ditemukan skor rata-rata indikator Procedural Justice Service dalam rangka memperbaiki kesalahan pelayanan yang diberikan kepada responden New d'Dhave Hotel Padang yang terdiri-dari 5 pertanyaan, dimana nilai rata-rata 3,60 Tingkat Capaian Responden (TCR) sebesar 72,00 \%. Menunjukan indikator Procedural Justice Service dalam rangka memperbaiki kesalahan pelayanan yang diberikan kepada responden New d'Dhave Hotel Padang dalam kategori Baik. Skor rata-rata indikator Interactional Justice dalam rangka memperbaiki kesalahan pelayanan yang diberikan kepada responden New d'Dhave Hotel Padang yang terdiri-dari 5 pertanyaan, dimana nilai rata-rata 3,54 Tingkat Capaian Responden (TCR) sebesar 70,80\%. Menunjukan indikator Interactional Justice dalam rangka memperbaiki kesalahan pelayanan yang diberikan kepada responden New d'Dhave Hotel Padang dalam kategori Baik. Kemudian skor rata-rata indikator Distributive Justice dalam rangka memperbaiki kesalahan pelayanan yang diberikan kepada responden New d'Dhave Hotel Padang yang terdiri-dari 3 pertanyaan, dimana nilai rata-rata 3,57 Tingkat Capaian Responden (TCR) sebesar 71,34 \%. Menunjukan indikator Distributive Justice dalam rangka memperbaiki kesalahan pelayanan yang diberikan kepada responden New d'Dhave Hotel Padang dalam kategori Baik.

Saran

Dalam memberikan pelayanan kepada pelanggan New d'Dhave Hotel Padang sudah baik sehingga pihak hotel dapat mempertahankan bahkan dapat meningkatkan pelayannnanya. Pelayanan merupakan hal yang paling penting dalam industry hotel, maka dari itu sebaiknya selalu diperhatikan.

\section{Daftar Pustaka}

Agusnawar. 2004. Resepsionis Hotel. Jakarta: PT Gramedia Pustaka Utama.

Gremler. 2016. Service Marketing Hotel. Fourth Edition.Prentice Hall; exclusive right by Mc Grawl Hill

Sunarno. 2006. Hotel Front Office Operationalis. Jakarta: PT. Gramedia Pustaka Utama

Tjiptono. 2011. Manajemen Jasa. Yogyakarta: Penerbit Andi Offset.

This is an open access article distributed under the Creative Commons 4.0 Attribution License, which permits unrestricted use, distribution, and reproduction in any medium, provided the original work is properly cited. $\odot 2017$ by author and Universitas Negeri Padang. 